\title{
FORMAÇÃO DOCENTE E AFETIVIDADE: CONCEPÇÕES SOBRE O PAPEL DA AFETIVIDADE NO DESENVOLVIMENTO INFANTIL
}

\author{
CONCEPTIONS OF FUTURE TEACHERS \\ CONCERNING THE ROLE OF AFFECTIVITY IN CHILD \\ DEVELOPMENT
}

\author{
Thamiris Christine Mendes \\ Priscila Larocca $^{* *}$
}

\begin{abstract}
RESUMO
A pesquisa visou identificar concepções de futuros docentes da Educação Infantil e Séries Iniciais do Ensino Fundamental sobre o papel da afetividade no desenvolvimento infantil. O referencial teórico provem dos estudos de Wallon, em que a afetividade constitui-se a primeira dimensão do psiquismo humano a desenvolver-se e a primeira forma de interação da criança com seu meio e com o outro. Embora, no início do desenvolvimento, os campos funcionais cognitivo, afetivo e motor encontrem-se sincreticamente misturados, estes conquistarão características próprias, mas se manterá uma dinâmica de reciprocidade em que avanços e dificuldades de um campo repercutem sobre outro. A pesquisa teve abordagem qualitativa, sendo a coleta de dados feita por meio de um questionário com três questões abertas, que permitiram aproximações com o sistema de crenças e concepções dos sujeitos da pesquisa, alunos dos primeiros e quartos anos de um Curso de Formação de Docentes. Nos resultados verificou-se a existência de um núcleo central de concepções focalizado na importância da dimensão afetiva para a relação professor-aluno e limitado aos aspectos desta relação como motivação, socialização e comportamento das crianças. Estas concepções não são suficientes para compreender o papel da dimensão afetiva na constituição da pessoa, pois os dados revelam que os futuros docentes compreendem a afetividade como aspecto complementar e secundário ao desenvolvimento infantil, enfatizando-se mais o desenvolvimento do intelecto como meta máxima da escola e desconsiderando-se totalmente a dimensão motora. Revela-se, pois, neste estudo uma representação intelectualista e fragmentada da criança em desenvolvimento.
\end{abstract}

Palavras-chave: Afetividade. Formação Docente. Henri Wallon. Desenvolvimento Infantil. Concepções.

\begin{abstract}
This research had as its goal the identification of conceptions of future teachers of Child Education and the first series of Fundamental School concerning the role of affectivity in child development. The theoretical references come from
\end{abstract}

\footnotetext{
“Pedagoga. Psicológa. Mestranda em educação na Universidade Estadual de Ponta Grossa.

** Pedagoga. Mestre e Doutora em educação pela UNICAMP. Professora da Universidade Estadual de Ponta Grossa
} 
the studies of Wallon, in which affectivity constitutes the first dimension of the human psyche to develop itself and the first interaction form between the child and her medium. Although in the beggining of development the fields of cognitive, affective and motor function are syncretically mixed, these will gain their own characteristics while at the same time maintaining a reciprocity dynamic in which advances and difficulties of one field reverberate one over the other. This research had a qualitative approach; the data collection was made through an open three questions questionnaire, which allowed approximations to the belief and conceptions systems of the subjects of the research, who were students of the first and fourth years of the Teachers Formation Course. In the results we verified the existence of a central nucleus of conceptions related to the importance of the affective dimension in the teacher-student relation and limited to the aspects of this dimension such as motivation, socialization and the behaviour of children. These conceptions are not enough to understand the role of the affective dimension in the constitution of the person; the data reveals that future teachers understand affectivity as a suplementar aspect, secondary in child development, laying emphasis on intelectual development as the school's biggest purpose, while at the same time completely disconsidering the motor dimensions. This research thus revealed an intelectualized and fragmented representation of the developing child.

Keywords: Affectivity. Teacher Formation. Henri Wallon. Child Development. Conceptions.

\section{Introdução e aproximações teóricas}

Estudos sobre crenças e teorias implícitas dos professores fundamentam a ideia de que o pensamento do professor é guiado por um sistema individual de crenças, valores e princípios que influenciam diretamente a sua prática pedagógica. Segundo Sadalla (2000), tais estudos buscam investigar tais crenças bem como as suas implicações para a ação docente. Este é o caso da investigação aqui apresentada, cujo objetivo visa identificar as concepções que docentes em formação possuem sobre o papel da afetividade no desenvolvimento da criança.

Quando se trata da temática da afetividade, em sua relação com o desenvolvimento infantil e com as práticas pedagógicas, é muito comum observar que as compreensões dos professores se centram nas manifestações físicas como o carinho, o beijo, o abraço ou o toque entre adultos e crianças, ou, simplesmente, admitem que a boa relação afetiva traz consequências positivas para que o professor se relacione com os seus alunos, seja por favorecer o clima das aulas, seja favorecendo a aprendizagem das crianças. No geral, os docentes não parecem compreender o significado complexo da influência da dimensão afetiva no desenvolvimento humano como um todo.

Segundo Leite (2006), tais compreensões não são arbitrárias, uma vez que retratam a herança da concepção dualista do ser humano que remonta à separação cartesiana entre corpo e alma, entre razão e emoção, entre a esfera cognitiva e a esfera afetiva. Para Leite (2006, p.16), “durante séculos o pensamento dominante sempre caracterizou a razão como a dimensão mais importante". Neste cenário, a emoção figurava como desagregadora da razão, devendo ser controlada e dominada por esta.

Como produto desta herança, os aspectos cognitivos do desenvolvimento humano historicamente obtiveram maior atenção dos estudiosos, especialmente no campo educacional.

Porém, muitos pesquisadores da atualidade tem dedicado esforços em questionar e fundamentar concepções e práticas educacionais que configuram uma visão integradora do homem. Entre eles, no contexto brasileiro, destacam-se Leite (2006) e 
Tassoni $(2001 ; 2006)$ que estudam as relações entre afetividade e prática pedagógica a partir dos pressupostos da Psicologia Histórico Cultural, com destaque às elaborações teóricas de Vygotsky e Wallon, ambos amparados pelo Materialismo Histórico Dialético.

Nesta perspectiva, a discussão da importância da dimensão afetiva na constituição humana passa necessariamente pela relação sujeito - objeto, que é central para a apropriação do conhecimento e para a própria constituição do sujeito. Os fundamentos da Psicologia Histórico Cultural mostram que a relação sujeito-objeto é marcada pelas mediações dos sistemas simbólicos compartilhados na cultura. (LEITE e TASSONI, 2002). Sendo assim, a qualidade afetiva das mediações exercidas pelos membros da cultura participa e intervem na relação sujeito-objeto, trazendo repercussões significativas (positivas ou negativas) sobre os processos de aprendizagem e de desenvolvimento das crianças. É importante mencionar aqui o que diz Pino (1997, p.2) para compreender o significado da intervenção dos mediadores na relação sujeito - objeto:

embora a atividade de conhecer pressuponha a existência do sujeito de determinadas propriedades que o habilitam a captar as características dos objetos, há fortes razões para pensar que o ato de conhecer não é obra exclusiva do sujeito, nem mesmo da sua interação [direta], mas da ação do elemento mediador, sem o qual não existe nem sujeito nem objeto de conhecimento.

Estas premissas permitem reconhecer que a relação que se estabelece entre sujeito cognoscente e objeto de conhecimento possui também certas qualidades afetivas favoráveis ou não, mas sempre com consequências para o processo de desenvolvimento de cada sujeito, que se apropria dos elementos da cultura, internalizando-os, tornando-os seus (plano intrapessoal) a partir das relações interpessoais. (VYGOTSKY, 1994). Portanto, é possível afirmar que no processo educativo escolar, a afetividade participa de todos os momentos da relação pedagógica, não se referindo apenas às relações mais imediatas entre professor e aluno.

Em relação à presente pesquisa, para melhor situar o papel da afetividade no desenvolvimento infantil, buscou-se a fundamentação da Teoria Psicogenética da Pessoa Completa de Henri Wallon, que considera o sujeito como ser completo e concreto e apresenta contribuições extremamente importantes no que se refere às considerações sobre o desenvolvimento infantil, a dimensão afetiva e a prática docente.

Wallon considera o ser humano como ser biologicamente social. É através da sua interação com o meio e com as outras pessoas que o sujeito se constitui.

A partir de uma perspectiva dialética do desenvolvimento humano, a teoria walloniana compreende que o psiquismo humano é composto por três campos funcionais: cognitivo, afetivo e motor. Cada uma destes possui importância no processo de desenvolvimento infantil e constituição da pessoa completa.

Os estudos de Wallon $(1968 ; 1971)$ acerca da relação Eu-Outro também demonstram que a afetividade se constitui como elemento diferenciador da espécie humana. Ao investigar as primeiras manifestações afetivas do ser humano, Wallon buscou conhecer suas características e entender as transformações que se dão na trajetória do desenvolvimento humano, concluindo que a afetividade tem um papel vital na constituição e no funcionamento intelectual, determinando também os interesses e necessidades individuais. Isto significa que "A afetividade também possibilita o avanço cognitivo, no sentido de que são os desejos, as intenções e os motivos que mobilizarão a criança na seleção das atividades e dos objetos". (TASSONI, 2001, p.230).

Nos pressupostos wallonianos é a afetividade que permite a criança apropriar-se dos instrumentos com os quais trabalha a atividade cognitiva (DANTAS, 1992). Em outras palavras, é por meio da afetividade que o sujeito ingressa no mundo simbólico que está na base de toda atividade cognitiva.

A relevância dada no presente estudo ao campo funcional afetivo acontece ainda pelo fato de que a afetividade constitui-se a primeira dimensão do psiquismo humano a desenvolver-se. É, portanto, a primeira etapa que a criança vivencia e a primeira forma de interação da criança com seu meio e com o outro.

No início do desenvolvimento, as dimensões cognitiva, afetiva e motora encontram-se sincreticamente misturadas, mas aos poucos cada 
uma conquistará características próprias, não deixando de existir entre elas uma dinâmica de reciprocidade ou mútua influência. (GALVÃO, 1995).

Assim que o bebê nasce, suas ações são voltadas à sobrevivência. Ele necessita do outro para sobreviver devido ao seu estado de imperícia e, para que suas necessidades sejam atendidas, precisa mobilizar o outro. Essa mobilização se dá, exclusivamente, através das emoções, da então denominada "afetividade primitiva", cuja base é orgânica. (DANTAS, 1992; GALVÃO, 1995). Por isso, Wallon coloca que a afetividade é a primeira dimensão que o sujeito vivencia, possuindo as funções de buscar a satisfação das necessidades e de se comunicar com o outro e com o mundo.

Conforme Galvão (1995), essa primeira forma de afetividade - a afetividade primitiva - evolui, e assim, passa de movimentos reflexos e orgânicos para movimentos cada vez mais expressivos e intencionais. Vale ressaltar que essa evolução só acontece através da interação e convivência com o outro.

Wallon coloca a existência de alguns princípios de desenvolvimento: alternância, predominância e integração funcional, os quais conferem dinamicidade ao desenvolvimento.

O princípio da alternância funcional caracteriza-se por dar direção a cada estágio do desenvolvimento. Segundo Dantas (1990, p. 7)

$\mathrm{Na}$ original concepção walloniana, as etapas da pessoa sucedem-se segundo um ritmo bifásico de abertura e fechamento para o mundo; a uma fase anabólica, centrípeta, de acúmulo de energia, voltada para a construção do Eu, sucede-se outra, que é centrífuga, catabólica, marcada pelo dispêndio energético e pela elaboração da realidade externa.

Isso significa que, em cada fase as atividades e comportamentos da criança assumem direções opostas, ora a direção está voltada para a construção de si (afetiva), ora voltada para a descoberta do mundo externo (cognitiva). No entanto é essencial compreender que tais direções, apesar de serem antagônicas, se complementam.

A predominância funcional acontece concomitantemente à alternância. Durante as etapas que a criança passa acontece o predomínio de atividades afetivas ou cognitivas, sendo que uma carrega aspectos da outra, havendo estreita reciprocidade en- tre esses dois campos, pois as conquistas de uma refletem permanentemente sobre a outra. (DANTAS, 1990; GALVÃO, 1995).

A integração funcional se refere à junção dos dois outros princípios (alternância e predominância). Assim, as funções cognitivas e afetivas constituirão um processo de integração. Galvão (1995, p. 45) evidencia:

Apesar de alternarem a dominância, afetividade e cognição não se mantém como funções exteriores uma à outra. Cada uma, ao reaparecer como atividade predominante num dado estágio, incorpora as conquistas realizadas pela outra, no estágio anterior, construindo-se reciprocamente, num permanente processo de integração e diferenciação.

Dessa maneira, a mutua influência entre afetividade e cognição resulta na integração dos dois campos funcionais, em que as funções mais evoluídas exercem controle sobre as mais arcaicas, não as omitindo. Existe, portanto, uma integração das condutas mais antigas com as mais recentes a fim de realizar um ajuste das reações às novas necessidades. (GALVÃO, 1995). No decorrer do processo, ao mesmo tempo em que há o predomínio de atividades voltadas para a construção de si, há momentos de predomínio para a elaboração do mundo exterior.

Deve-se destacar ainda que, além da afetividade e da inteligência, a motricidade exerce papel imprescindível para tais dimensões do processo de desenvolvimento, estando também interligada às primeiras..

Ao longo do desenvolvimento, o campo funcional do movimento é um dos primeiros a se desenvolver fornecendo base para os outros campos: da afetividade e da inteligência. É por isso que a Wallon enfatizava na dimensão motora seu aspecto expressivo (sua função expressiva), o que chama de dimensão afetiva do movimento. Essa função afetiva do movimento acontece porque antes mesmo de exercer influência sobre o meio físico, o movimento age sobre o meio humano mobilizando as pessoas ao seu redor o que garante seu caráter expressivo. $\mathrm{Ou}$ seja, é nessa primeira atuação do movimento sobre o meio das pessoas que caracteriza a importância dada por Wallon à dimensão motora.

O movimento age sobre o meio humano antes mesmo de agir sobre o meio físico, o que assinala seu caráter expressivo, portanto, é por isso que Wallon 
coloca que a primeira manifestação do movimento da criança é de direção afetiva (GALVÃO, 1995). No que diz respeito a isso, Dantas (1992, p. 39) coloca que "A maior parte das manifestações motoras consistirão em gestos dirigidos às pessoas (apelo): manifestações, agora cheias de nuances, de alegria, surpresa, tristeza, desapontamento, expectativa, etc".

Dantas (1992) esclarece que para a teoria walloniana o ato mental (pensamento) se desenvolve a partir do ato motor (movimento) e em seguida inibe-o sem que o mesmo deixe de ser atividade corporal. No decorrer do desenvolvimento, os movimentos deixam de ser puramente instrumentais e ganham caráter cada vez mais expressivo, mesmo o corpo ficando cada vez mais "parado", pois, movimento não significa estar se mexendo o tempo todo.

Galvão (1995, p. 71) explica sobre a existência de uma relação de reciprocidade entre função postural e o pensamento, pois, a primeira fornece base para a segunda e, ao mesmo tempo, reflete o pensamento. "A criança reage corporalmente aos estímulos exteriores, adotando posturas ou expressões, isto é, atitudes, de acordo com as sensações experimentadas em cada situação." Gradualmente o movimento integra-se à inteligência. Tal processo resulta em uma redução da motricidade exterior.

Assim, o desenvolvimento da dimensão cognitiva do movimento torna a criança mais autônoma para agir sobre o mundo, diminuindo a dependência do adulto, que antes mediava a ação da criança sobre o mundo. No início do desenvolvimento os movimentos possuem função de sobrevivência para bebê, conforme o sujeito se desenvolve o campo funcional motor também se desenvolve, e ganha características expressivas que melhoram sua relação com o mundo e lhe permite maior autonomia na medida em que sua dependência total do outro diminui. (GALVÃO, 1995). Portanto, o movimento é também constitutivo das relações que o sujeito estabelece ao longo da vida.

É por esses motivos que os professores precisam ter conhecimento da dinâmica de integração entre os campos funcionais e do processo de desenvolvimento infantil.

É nesse sentido que a abordagem psicogenética de Wallon contribui para a noção de ser humano como sujeito completo, formado pelas dimensões afetiva, cognitiva e motora. Esta concepção caminha no sentido de superar o pensamento dicotômico entre mente e corpo ainda muito presente na atualidade.

Considerando-se que, para Wallon, a afetividade é essencial e decisiva para a constituição do sujeito, e encontra-se extremamente relacionada ao desenvolvimento cognitivo e motor, ressalta-se a importância de identificar quais as concepções de futuros docentes sobre o papel da afetividade no desenvolvimento da criança. Acreditamos que a partir deste conhecimento será possível conhecer e questionar suas crenças e representações, a fim de buscar um conhecimento mais científico e elaborado acerca da temática.

\section{Metodologia}

A pesquisa delineou-se a partir de procedimentos quantitativos e qualitativos. Considerou-se que, quantidade e qualidade não se excluem, nem são necessariamente contraditórias entre si. Num enfoque dialético, qualidade e quantidade são categorias que, embora opostas, pertencem à mesma unidade, devendo ser compreendidas a partir do princípio dialético do movimento. Como explica Gamboa (2002, p. 105):

\begin{abstract}
Essas categorias modificam-se, complementam-se e transformam-se uma na outra e vice versa, quando aplicadas a um mesmo fenômeno. De fato, as duas dimensões [qualidade e quantidade] não se opõem, mas se inter-relacionam [sic] como duas fases do real num movimento cumulativo e transformador, de tal maneira que não podemos concebê-las uma sem a outra, nem uma separada da outra.
\end{abstract}

Os procedimentos quantitativos são indicados para conhecer ou comprovar evidências, investigar a amplitude ou extensão de um dado fenômeno, ou ainda, conhecer regularidades, indicadores e/ou tendências presentes em uma dada realidade. São procedimentos que quantificam os dados coletados, buscando-se estabelecer entre eles relações matemáticas.

A pesquisa qualitativa, por sua vez, é indicada para trabalhar com dados relacionados a valores, representações, atitudes, crenças, hábitos etc. Chizzotti (2006, p.28) explica que o termo qualitativo 
frequentemente abarca diferentes tradições de pesquisa, mas o ponto comum é a investigação de fenômenos humanos dotados de significados.

$\mathrm{O}$ instrumento elaborado para a coleta dos dados foi um questionário composto por três questões abertas, que visaram identificar as concepções dos alunos dos primeiros e quartos anos do Curso de Formação de Docentes do Instituto de Educação Professor César Prieto Martinez, Ponta Grossa - PR, sobre a dimensão afetiva e suas contribuições para os processos de aprendizagem e desenvolvimento das crianças da Educação Infantil e Séries Iniciais do Ensino Fundamental.

Por meio do questionário buscou-se primeiramente identificar as contribuições da afetividade para o desenvolvimento e aprendizagem das crianças da Educação Infantil e séries iniciais do Ensino Fundamental, solicitando aos participantes que relatassem experiências, situações ou exemplos que deveriam ser enumerados progressivamente de acordo com o grau de importância atribuído pelo participante àquela experiência. A segunda questão solicitou a justificativa da escolha da situação relatada em primeiro lugar na questão anterior. A terceira questão buscou fazer com que os participantes elencassem os aspectos do desenvolvimento e da aprendizagem da criança que são beneficiados pela afetividade na sala de aula.

Foram respondidos 92 questionários, dos quais 45 referentes aos primeiros anos do Curso de Formação de Docentes e 47 aos quartos anos. Para a análise empregaram-se tanto o tratamento estatístico, como o estudo dos núcleos de significação encontrados nas respostas.

A seguir apresentamos os resultados encontrados e a consequente análise.

\section{Contribuições da afetividade para o desenvolvimento da criança}

Os dados obtidos com os primeiros anos revelaram um núcleo central de concepções concentrado em três categorias de significado principais: Relação professor-aluno, Socialização da criança e Motivação para a aprendizagem.

A primeira categoria, Relação professor-aluno, obteve $77,7 \%$ das respostas, e sugere que os alunos compreendem a afetividade especialmen- te no campo interrelacional, envolvendo elementos como diálogo, confiança, respeito, amor e carinho e também atenção e tratamento igual para todos os alunos. Exemplo disso foi o sujeito $1 \mathrm{~S}_{5}{ }^{1}$ que colocou: "A professora e o aluno podem ter uma relação melhor". Para o sujeito esta relação afetiva torna possível o diálogo entre educador e educando, favorecendo a relação entre eles.

A concepção que atingiu segundo lugar, com um percentual de 27,2\%, foi Motivação para a aprendizagem. Ficou evidente nas respostas que a afetividade é condição essencial para que a criança seja motivada a aprender, e também a gostar de ir à escola e gostar de estudar. Os sujeitos explicam que "A criança tem que ser incentivada" $1 S_{13}$, "Ela aprende com mais interesse" e "faz as coisas com entusiasmo" $1 S_{6}$. Em tais respostas, os sujeitos estabelecem conexão entre a afetividade e o incentivo das crianças em ir para a escola, o interesse, a vontade e o entusiasmo para a aprendizagem o que torna o processo mais prazeroso para os alunos.

A terceira concepção - Socialização da criança - cujo percentual foi $18,1 \%$ refere-se a respostas que enfatizam o convívio da criança com as demais e com os adultos. Note-se: " $A$ interação uma com a outra, e com os professores" $1 S_{14}$; "Um bom diálogo e uma boa convivência por ex: uma turma que não tem um bom convívio com o professor provavelmente não terão boas notas" $1 S_{26}$. A partir destas respostas, percebe-se que os sujeitos concebem que a dimensão afetiva influi de maneira decisiva para a socialização infantil, contribuindo para um ambiente de interações bem sucedidas na escola, que seja saudável e estimulante da boa convivência entre alunos e professores.

Além das principais concepções citadas, verificamos ainda nas respostas das turmas dos primeiros anos, a presença de outras cinco concepções que não atingiram uma frequência superior que $10 \%$, e, portanto, não foram consideradas como importantes para a nossa análise.

Em relação aos dados dos alunos dos quartos anos, as respostas confirmaram as principais concepções encontradas nos primeiros anos, embora

\footnotetext{
${ }^{1} \mathrm{O}$ primeiro número se refere à série $\left(1=1^{\mathrm{a}}\right.$ série; $4=4^{\mathrm{a}}$ série $) ; \mathrm{S}=$ sujeito; $5=$ número do sujeito.
} 
com frequência diferenciada: Relação professor-aluno (40,4\%), Motivação para a aprendizagem $(28,2 \%)$ e Socialização da criança $(21,4 \%)$.

Nas duas primeiras concepções, os sujeitos compreendem que a afetividade é essencial para desenvolver as relações interpessoais em sala de aula, destacando que esta se relaciona diretamente com a vontade e interesse dos alunos pelo estudo, pela participação das crianças nas atividades e nas aulas, o esforço para fazer o melhor e o incentivo e interesse em ir para a escola. Observamos algumas expressões que os alunos utilizaram nestes núcleos de significado: confiança, proximidade do professor, laços de amizade, respeito, amor, carinho, compreensão e atenção. Também concebem que, a partir da dimensão afetiva presente no ambiente escolar, as crianças podem sentir prazer em ir para a aula, tornando o processo de ensino-aprendizagem prazeroso, como ilustrado nas seguintes respostas: "Com afeto terá mais interesse em aprender" e $4 S_{21}$; "O aluno terá mais vontade de ir para escola" $4 S_{35}$.

Sobre a concepção Socialização da criança os sujeitos, ao colocar que a dimensão afetiva promove o desenvolvimento da sociabilidade das crianças, enfatizam os significados das interações sociais e da comunicação. Nessa concepção, os afetos agem como facilitadores da socialização, fazendo com que as crianças interajam entre si promovendo assim o desenvolvimento da sociabilidade.

Embora as representações prevalentes nos primeiros e nos quartos anos estejam voltadas para a relação professor e aluno, percebe-se uma diversidade de compreensões e preocupações que envolvem a dimensão afetiva, como se pode notar nas tabelas 1 e 2 .

Tabela 1 - Tipos e frequência de concepções encontradas nos primeiros anos referentes à primeira questão

\begin{tabular}{l|c}
\hline \multicolumn{1}{c|}{ Concepções } & Frequência \\
\hline 1. Relação professor-aluno & $77,7 \%$ \\
\hline 2. Motivação para a aprendizagem & $27,2 \%$ \\
\hline 3. Socialização da criança & $18,1 \%$ \\
\hline 4. Liberdade de expressão & $9,3 \%$ \\
\hline 5. Facilitação da aprendizagem & $9,0 \%$ \\
\hline 6. Desenvolvimento cognitivo & $3,8 \%$ \\
\hline 7. Comportamento & $3,8 \%$ \\
\hline 8. Escola como compensadora & $3,8 \%$ \\
\hline
\end{tabular}

Fonte: As autoras
Tabela 2 - Tipos e frequência de concepções encontradas nos quartos anos referentes à primeira questão

\begin{tabular}{l|c}
\hline \multicolumn{1}{c|}{ Concepções } & Frequência \\
\hline 1. Relação professor-aluno & $40,4 \%$ \\
\hline 2. Motivação para a aprendizagem & $28,2 \%$ \\
\hline 3. Socialização da criança & $21,4 \%$ \\
\hline 4. Desenvolvimento moral & $8,5 \%$ \\
\hline 5. Comportamento & $7,4 \%$ \\
\hline 6. Participação da família & $7,4 \%$ \\
\hline 7. Escola como compensadora & $4,4 \%$ \\
\hline 8. Desenvolvimento da autoconfiança e & $4,3 \%$ \\
\hline autoestima & $4,3 \%$ \\
\hline 9. Desenvolvimento emocional & $4,2 \%$ \\
\hline 10. Desenvolvimento da criatividade & $3,7 \%$ \\
\hline 12. Desenvolvimento psicológico & $3,7 \%$ \\
\hline 13. Desenvolvimento de habilidades & $3.7 \%$ \\
\hline 14. Desenvolvimento motor & $2,4 \%$ \\
\hline 15. Diminuição de conflitos em sala & $2,4 \%$ \\
\hline 16. Desenvolvimento cognitivo & $2,4 \%$ \\
\hline 17. Desenvolvimento da autonomia & $2,2 \%$ \\
\hline 18. Solidariedade & $2,2 \%$ \\
\hline 19. Desenvolvimento integral & $2,2 \%$ \\
\hline 20. Desenvolvimento psicológico & $2,2 \%$ \\
\hline 21. Liberdade de expressão & $2,1 \%$ \\
\hline
\end{tabular}

Fonte: As autoras

Os dados expostos levam a compreender que os alunos possuem conhecimentos significativos sobre a afetividade, o que não significa a compreensão da mesma a partir da teoria de Wallon, considerando o desenvolvimento da pessoa como uma totalidade.

\section{Justificativa sobre as contribuições da afetividade para o desenvolvimento infantil}

Nas justificativas que os participantes deram sobre as contribuições da afetividade para o desenvolvimento infantil, os dados obtidos com os primeiros anos do curso demonstram duas principais concepções: Relação professor-aluno e Motivação e facilitação da aprendizagem.

$\mathrm{Na}$ categoria Relação professor-aluno, com $53,3 \%$, as respostas tendem a considerar que a dimensão afetiva está apenas condicionada à atenção do professor com o aluno, ao sentimento de confiança que deve ser construído nessa relação, a existência 
de amor, carinho e compreensão, além da amizade. Por exemplo: "Porque primeiro de tudo para ficar mais fácil tem que ter um bom relacionamento com o professor que tudo da certo." $1 S_{22}$.

Com 24,4\%, a concepção Motivação e facilitação da aprendizagem indica que os alunos possuem uma visão muito clara de que as relações afetivas que professores e alunos desenvolvem são decisivas para motivar as crianças a irem à escola e bem desempenhar-se no processo de aprendizagem.

Nas respostas dos estudantes dos quartos anos do Curso de Formação Docente identificaram-se três concepções principais: Relação professor-aluno, Motivação e facilitação da aprendizagem e Desenvolvimento da autoconfiança e autoestima.

A concepção que atingiu maior frequência foi Relação professor-aluno (29,7\%), assim como nos primeiros anos. Fica evidente que, para os sujeitos dos quartos anos do magistério, a dimensão afetiva se conecta, primeiramente, com aspectos dos relacionamentos interpessoais presentes nas escolas com ênfase no respeito, amor, carinho e amizade do professor com seus alunos.

No que se refere à concepção Motivação e facilitação da aprendizagem, com 19,1\%, as alunas $4 S_{27}$ e $4 S_{38}$ explicam: "com amor e carinho ele terá muito mais vontade de aprender e de ir para a escola..." "Quando o professor demonstra interesse em ensinar a criança começa a se interessar em aprender". Os alunos compreendem que para que as crianças aprendam é essencial que, em primeiro lugar, elas se sintam motivadas para o processo. A concepção Desenvolvimento da autoconfiança e autoestima, com $12,7 \%$, foi observada pela primeira vez nos dados. Para exemplificar temos a resposta do sujeito $4 \mathrm{~S}_{41}$ : "Através da relação afetiva que o professor tem com o aluno, este se sente importante e acaba sendo motivado a participar das atividades".

Os alunos entendem que por meio da afetividade é possível estimular o desenvolvimento de aspectos como autoconfiança e autoestima, pois, quando há relações de afeto as crianças são encorajadas e valorizadas, o que gera um sentimento de segurança que influi no processo de aprendizagem.

Vale ressaltar que as respostas dos primeiros anos referentes à segunda questão encontram-se distribuídas em sete concepções, já nos quartos anos encontramos treze categorias diferenciadas de concepções, o que sugere que também há uma ampliação das considerações sobre a afetividade durante o curso. Observem-se as tabelas 3 e 4

Tabela 3 - Tipos e frequência de concepções encontradas nos primeiros anos referentes à segunda questão

\begin{tabular}{l|c}
\hline \multicolumn{1}{c|}{ Concepções } & Frequência \\
\hline 1. Relação professor-aluno & $53,3 \%$ \\
\hline 2. Motivação e facilitação da aprendizagem & $24,4 \%$ \\
\hline 3. Liberdade de expressão & $6,6 \%$ \\
\hline 4. Aulas prazerosas & $6,6 \%$ \\
\hline $\begin{array}{l}\text { 5. Desenvolvimento da autoconfiança e } \\
\text { autoestima }\end{array}$ & $4,4 \%$ \\
\hline 6. Socialização da criança & $2,2 \%$ \\
\hline 7. Escola como compensadora & $2,2 \%$ \\
\hline
\end{tabular}

Fonte: As autoras

Tabela 4 - Tipos e frequência de concepções encontradas nos quartos anosreferentes à segunda questão

\begin{tabular}{l|c}
\hline \multicolumn{1}{c|}{ Concepções } & Frequência \\
\hline 1. Relação professor-aluno & $29,7 \%$ \\
2. Motivação e facilitação da aprendizagem & $19,1 \%$ \\
3. Desenvolvimento da autoconfiança e & $12,7 \%$ \\
autoestima & $8,5 \%$ \\
4. Escola como compensadora & $8,2 \%$ \\
5. Desenvolvimento moral & $4,2 \%$ \\
6. Desenvolvimento cognitivo & $4,2 \%$ \\
7. Desenvolvimento da criatividade & $2,1 \%$ \\
8. Liberdade de expressão & $2,1 \%$ \\
9. Desenvolvimento integral & $2,1 \%$ \\
10. Solidariedade & $2,1 \%$ \\
11. Melhor desempenho escolar & $2,1 \%$ \\
12. Desenvolvimento psicológico & $2,1 \%$ \\
13. Desenvolvimento da personalidade & \\
\hline
\end{tabular}

Fonte: As autoras

As concepções mais frequentes em ambas as turmas são: Relação professor-aluno e Motivação e Facilitação da aprendizagem, sendo o Desenvolvimento da Autoconfiança e Autoestima um núcleo de concepções mais significativo nos quartos anos do Curso. 


\section{Aspectos do desenvolvimento e da aprendizagem da criança que são beneficiados pela afetividade}

Sobre os aspectos do desenvolvimento e da aprendizagem beneficiados pela afetividade, as principais concepções observadas nos primeiros anos foram: Relação professor-aluno (45,4\%), Motivação e facilitação da aprendizagem $(29,4 \%)$ e Comportamento $(13,6 \%)$.

$\mathrm{Na}$ primeira categoria analisamos respostas como as de $1 \mathrm{~S}_{5}$ e $1 \mathrm{~S}_{7}$ sugerindo que a partir de um bom relacionamento na escola os alunos prestam mais atenção nas aulas e aprendem mais: "se a criança gosta do professor consequentemente ela vai gostar de sua aula, prestando atenção e aprendendo..." e "Quando temos um bom relacionamento com o professor a gente presta mais atenção...". Notamos que os sujeitos consideram que a dimensão afetiva está ligada às relações sociais desenvolvidas no espaço escolar.

$\mathrm{Na}$ concepção Motivação e facilitação da aprendizagem os alunos dos primeiros anos destacam que o fato de a criança gostar de seu professor é condição essencial para que haja desenvolvimento da inteligência, e também torna o processo de aprendizagem alegre e prazeroso.

A categoria Comportamento que, pela primeira vez, demonstra frequência significativa para análise, estabelece ligação entre a afetividade e o comportamento das crianças, demonstrando que os participantes dos primeiros anos concebem que a afetividade presente na relação professoraluno repercute nas atitudes e ações das crianças exercendo forte influência sobre o modo que as mesmas se comportam. Notam-se os exemplos: "O comportamento da criança pode ser melhor..." $1 S_{6}$; "... isso pode ajudar o aluno a se comportar $e$ aprender melhor" $1 S_{27}$.

As respostas dos alunos dos quartos anos do curso concentraram-se em cinco principais concepções: Motivação e facilitação da aprendizagem, Desenvolvimento cognitivo, Comportamento, Relação professor-aluno e Desenvolvimento da autoconfiança e autoestima.

$\mathrm{Na}$ concepção Motivação e facilitação da aprendizagem, com 40,4\%, aparecem respostas que evidenciam a dimensão afetiva como importante para o interesse das crianças pelo estudo bem como para a facilitação do processo de aprendizagem.

Em Desenvolvimento cognitivo, com frequência de $29,7 \%$, demonstra-se que os sujeitos relacionam a dimensão afetiva com a dimensão do conhecimento. Notam-se os exemplos: “...ajuda no seu intelecto..." $4 S_{42}$; $e$ "... a afetividade entre professor e aluno beneficia a criança a desenvolver o intelecto" $4 S_{43}$.

Com $17 \%$ de frequência, a concepção Comportamento demonstra que os sujeitos concebem que a afetividade influencia na maneira de agir dos alunos em sala de aula, tornando-os mais obedientes.

A concepção Relação professor-aluno obteve $14,8 \%$, sugerindo que os alunos dos últimos anos do curso relacionam a afetividade com: atenção, amor, carinho, confiança, respeito e amizade.

Com $12,7 \%$ a concepção Desenvolvimento da autoconfiança e autoestima atenta para a influência da dimensão afetiva para o desenvolvimento do Eu. Para exemplificar: "a autoestima aumenta, ele confia mais nele mesmo" $4 S_{45}$; e "O aluno se sente mais seguro..." $4 S_{9}$.

Observou-se que houve maior amplitude de significados nas concepções dos quartos anos, em relação aos primeiros, pois as respostas encontram-se mais diversificadas. Entretanto, essa diversificação não é considerável para concluirmos que os sujeitos compreendem as contribuições da dimensão afetiva numa perspectiva de desenvolvimento integral da pessoa completa. As tabelas 5 e 6 permitem verificar os significados encontrados e suas frequências.

Tabela 5 - Tipos e frequência de concepções encontradas nos primeiros anos referentes à terceira questão

\begin{tabular}{l|c}
\multicolumn{1}{c|}{ Concepções } & Frequência \\
\hline 1. Relação professor-aluno & $45,4 \%$ \\
\hline 2. Motivação e facilitação da aprendizagem & $29,54 \%$ \\
\hline 3. Comportamento & $13,6 \%$ \\
\hline 4. Liberdade de expressão & $6,8 \%$ \\
\hline 5. Socialização da criança & $4,5 \%$ \\
\hline 6. Desenvolvimento cognitivo & $2,2 \%$ \\
\hline 7. Aulas prazerosas & $2.2 \%$ \\
\hline 8. Desenvolvimento integral & $2,2 \%$ \\
\hline
\end{tabular}

Fonte: As autoras 
Tabela 6 - Tipos e frequência de concepções encontradas nos quartos anos referentes à terceira questão

\begin{tabular}{l|c}
\hline \multicolumn{1}{c|}{ Concepções } & Frequência \\
\hline 1. Motivação e facilitação para a aprendizagem & $40,4 \%$ \\
2. Desenvolvimento cognitivo & $29,7 \%$ \\
3. Comportamento & $17 \%$ \\
4. Relação Professor-aluno & $14,8 \%$ \\
5. Desenvolvimento da autoconfiança e da & $12,7 \%$ \\
autoestima & $8,2 \%$ \\
6. Melhor desempenho escolar & $6,3 \%$ \\
7. Socialização da criança & $4,2 \%$ \\
8. Desenvolvimento moral & $4,2 \%$ \\
9. Desenvolvimento emocional & $2,1 \%$ \\
10. Liberdade de expressão & $2,1 \%$ \\
11. Desenvolvimento da personalidade & $2,1 \%$ \\
12. Escola como compensadora & \\
\hline
\end{tabular}

Fonte: As autoras

Observe-se a maior amplitude das concepções nos quartos anos em relação aos primeiros. Entretanto, considerando-se o conjunto de dados essa diversificação não é considerável para concluir que os sujeitos compreendem as contribuições da dimensão afetiva numa perspectiva de desenvolvimento integral da pessoa completa.

\section{Discussão e análise dos resultados}

O núcleo central das concepções dos alunos dos primeiros e dos quartos anos do curso de magistério concentra-se na importância da afetividade para a relação professor-aluno. Os sujeitos compreendem a estreita ligação entre a dimensão afetiva e aspectos dos relacionamentos interpessoais vivenciados no espaço escolar, o que nos sugere que concebem que a criança se desenvolve a partir das interações com outras pessoas.

Os docentes em formação entendem que, para haja um processo de desenvolvimento infantil adequado, é imprescindível que as crianças interajam com o seu meio e com outras pessoas, influenciando assim o processo de socialização.

Ambas as séries compreendem que a criação do vínculo afetivo entre professor e aluno é essencial para facilitar a aprendizagem e traz consequências para o desempenho escolar da criança. Portanto, as concepções identificadas demonstram que os alunos dos primeiros e quartos anos compreendem que há uma relação entre afetividade e inteligência.

Entretanto, apesar de conceberem tal relação, a mesma acontece no sentido de que a dimensão afetiva é, ainda, apenas um componente, ou uma condição enriquecedora, para que o objetivo maior da educação seja atendido: o desenvolvimento intelectual da criança. Portanto, prevalece a dimensão cognitiva, sendo que a afetividade ocupa lugar secundário no processo educativo.

De acordo com a teoria walloniana, é principalmente nas interações com as outras pessoas e com seu meio que o sujeito se constitui. Nesse sentido Wallon destaca que ao mesmo tempo em que é biológico, o sujeito é também social, pois, apenas com o desenvolvimento do sistema nervoso não há aquisição de condutas psicológicas superiores como a linguagem, por exemplo. É necessário que haja interação com a cultura, o "alimento cultural", como denomina Galvão (1995, p. 41), para que haja a construção do sujeito como pessoa.

Compreende-se que, na psicogenética walloniana, o desenvolvimento é extremamente dependente do contexto em que o sujeito se encontra, dos meios que o mesmo oferece e também do "uso" que o sujeito faz desse contexto. (GALVÃO, 1995).

Para Wallon, a escola deve ter como objetivo primordial o desenvolvimento integral da pessoa envolvendo todas as dimensões do psiquismo humano: a afetiva, a cognitiva e também a motora, e não deve apenas focar a construção do conhecimento.

Conforme Bastos e Pereira (2003), a dimensão afetiva contribui sim para o processo de aprendizagem, mas não quer dizer que seja apenas essa a característica da afetividade.

Chamou a atenção nos dados dos participantes do Curso de Formação de Docentes, a total ausência de concepções ou sigificações voltadas para a relação entre afetividade e movimento. Isto demonstra a prevalência da ideia de sujeito como ser "fragmentado", em que as dimensões do psiquismo se desenvolvem umas independentemente das outras, não havendo considerações do sujeito como ser completo e concreto, constituído na dinamicidade das trocas entre os seus campos funcionais.

Os alunos de ambas as séries demonstram também conceber que a afetividade entre professoraluno auxilia no processo de aprendizagem no 
sentido de ajudar a "controlar" o comportamento das crianças, pois elas se tornam "mais comportadas", "menos agitadas", mais obedientes. Desse modo, nota-se que as compreensões sobre o papel da afetividade no desenvolvimento da criança são atravessadas por concepções comportamentais, pautadas por ideias de que a criança deve ser condicionada, compreensão essa que nega o caráter dialético da das trocas funcionais entre afeto, inteligência e motricidade para a constituição do ser.

Os alunos dos quartos anos demonstraram uma concepção que coloca a autoestima e a autoconfiança da criança, considerando que estas se beneficiam da afetividade entre professor e alunos, representação esta que não se fez presente nos primeiros anos do curso, fazendo-se perceber que houve um avanço na compreensão do papel da afetividade.

Conforme Barros (2006, p.172), a autoestima e a autoconfiança se traduzem em atitudes positivas do indivíduo em relação a si próprio e ao mundo, como também muda a natureza afetiva da relação dos alunos com os conteúdos escolares. Para a autora "a autoestima é um conceito que ajuda a entender os efeitos da prática pedagógica". Quando o aluno se considera capaz, isso traz consequências para a relação sujeito - objeto, e, portanto para a construção da sua inteligência.

No entanto, percebeu-se também que para os participantes o objetivo maior da educação consiste em promover o desenvolvimento intelectual dos alunos.

A partir dessa análise, observamos que as concepções que os futuros professores possuem sobre a afetividade na prática pedagógica encontram-se limitadas aos aspectos da relação professor-aluno, motivação, socialização e comportamento das crianças. Estas concepções não são suficientes para que os sujeitos compreendam a importância da dimensão afetiva para a constituição da pessoa completa, conforme a teoria walloniana, na medida em que destacam a afetividade como fator complementar ao processo de desenvolvimento infantil, e enfatizam sempre o desenvolvimento do intelecto como meta máxima. Revelou-se, pois, uma representação intelectualista e fragmentada da pessoa.

\section{Considerações finais}

Nesta pesquisa identificamos as concepções de alunos dos primeiros e quartos anos do curso de formação de docentes sobre a dimensão afetiva.

A partir da teoria psicogenética da pessoa completa proposta por Wallon, que concebe o sujeito como ser completo e concreto e se desenvolve mutuamente em suas dimensões motora, afetiva e cognitiva, destacamos o papel central da afetividade no desenvolvimento infantil, pois, a mesma é o primeiro "instrumento" que a criança possui para comunicar-se com o mundo e para que suas necessidades mais básicas sejam satisfeitas.

A análise das concepções obtidas nos mostra que os sujeitos concebem a afetividade como dimensão secundária do desenvolvimento infantil considerando como meta máxima da educação o desenvolvimento intelectual. Como consequência disso, as concepções demonstram que os futuros professores possuem uma visão de homem como sujeito fragmentado, pois o foco se centra no intelecto desconsiderando assim as outras dimensões da pessoa: a motora e a afetiva.

Embora se tenha verificado uma ampliação e diversificação das concepções dos quartos anos em relação aos primeiros, percebe-se que essa evolução de pensamento não é significativa no sentido de fornecer aos alunos a compreensão da importância da dimensão afetiva no desenvolvimento da criança e a visão de sujeito em sua totalidade conforme considera Wallon.

No que diz respeito ao papel da afetividade na prática pedagógica os sujeitos investigados reconhecem sua importância somente no sentido de que tal dimensão auxilia no desenvolvimento do intelecto, e nas relações interpessoais.

A pesquisa nos permitiu concluir que, ao longo do tempo, o aluno do curso de magistério passa a perceber que a afetividade está relacionada a outros aspectos da educação que não apenas à motivação das crianças ou ao tipo de relações existentes entre professor e aluno. Os dados coletados nos permitem dizer que há uma evolução de pensamento das primeiras para as quartas séries do curso de formação docente, mesmo que pouco significativa, sobre a dimensão afetiva na prática pedagógica e suas influências no desenvolvimento infantil. 


\section{Referências}

BARROS, Flávia R. Mediação e afetividade: histórias de mudanças na relação sujeito -objeto. In: LEITE, Sérgio. A. da S. (Org.). Afetividade e práticas pedagógicas. São Paulo: Casa do Psicólogo, 2006, p. 147-174.

BASTOS, Ivanilda Maria e Silva; PEREIRA, Sonia Regina. Contribuição de Vygotsky e Wallon para o desenvolvimento infantil. Linhas, Florianópolis, v. 4, n. 1, jan./jun., 2003. Disponível em: http://www.periodicos.udesc.br/index.php/ linhas/article/viewFile/1206/1021>. Acesso em: 14 set. 2011.

CHIZZOTTI, Antonio. Pesquisa qualitativa em ciências humanas e sociais. Petrópolis: RJ: Vozes, 2006.

DANTAS, Heloysa. A infância da razão: uma introdução à psicologia da inteligência de Henri Wallon. São Paulo: Manole Dois, 1990.

DANTAS, Heloysa. A afetividade e a construção do sujeito na psicogenética de Wallon. In: LA TAILLE, Yves. Piaget, Vygotsky, Wallon: teorias psicogenéticas em discussão. São Paulo: Summus, 1992, p. 85-98.

GALVÃO, Izabel. Henri Wallon: uma concepção dialética do desenvolvimento infantil. 4. ed. Petrópolis, Rio de Janeiro: Vozes, 1995.

GAMBOA, Sílvio Sanchez . Quantidade - qualidade: para além de um dualismo técnico e de uma dicotomia epistemológica. In: GAMBOA, Sílvio Sanchez e SANTOS FILHO, José Camilo. (Org.) Pesquisa educacional: quantidade - qualidade. 5 ed. São Paulo: Cortez,2002.

LEITE, Sérgio Antonio da Silva. Afetividade e práticas pedagógicas. In: . (Org.). Afetividade e práticas pedagógicas. São Paulo: Casa do Psicólogo, 2006, p. 15-45.

LEITE, Sérgio Antonio da Silva; TASSONI, E. C. M. A afetividade em sala de aula: as condições de ensino e a mediação. In: AZZI, R.; SADALLA, A. M. F. A. Psicologia e formação docente: desafios e conversas. São Paulo: Casa do Psicólogo, 2002.

PINO, A. O biológico e o cultural nos processos cognitivos. IN: Linguagem, cultura e cognição: reflexão para o ensino de Ciências. Anais do Encontro sobre Teoria e Pesquisa em Ensino de Ciências. Campinas: Faculdade de Educação, UNICAMP, 1997, p.5-24.

SADALLA, Ana Maria Falcão de Aragão et al. Teorias implícitas na ação docente: contribuição teórica ao desenvolvimento do professor prático-reflexivo. In: AZZI, Roberta G.; BATISTA, Sylvia H. S. da S.; SADALLA, Ana Maria F. de A. (Orgs.). Formação de professores: discutindo o ensino de psicologia. Campinas, SP: Alínea, 2000. p. 21-38.

TASSONI, Elvira Cristina M. A afetividade e o processo de apropriação da linguagem escrita. In: LEITE, Sérgio
Antonio da Silva . (Org.). Alfabetização e letramento: contribuições para as práticas pedagógicas. Campinas, SP: Komedi: Arte Escrita, 2001.

TASSONI, Elvira Cristina M. Dimensões afetivas na relação professor-aluno. In: LEITE, Sérgio Antonio da Silva . (Org.). Afetividade e práticas pedagógicas. São Paulo: Casa do Psicólogo, 2006, p.47- 74.

VYGOTSKY, L. S. A formação social da mente. São Paulo: Martins Fontes, 1994.

WALLON, H. A evolução psicológica da criança. Lisboa: EDIÇÕES 70, 1968.

As origens do caráter na criança. São Paulo: Difusão Europeia do Livro, 1971.

Artigo Submetido: 12/05/2012

Artigo Aprovado: 18/04/2013 